\title{
Role of nifedipine in treatment of hypertension
}

\author{
M B MURPHY, A J I SCRIVEN, C T DOLLERY
}

\begin{abstract}
The efficacy of nifedipine in the treatment of hypertension was assessed in 15 patients whose hypertension continued while being treated with atenolol $100 \mathrm{mg}$ and bendrofluazide $5 \mathrm{mg}$ daily. Nifedipine was added in doses of 10,20 , and $30 \mathrm{mg}$ three times daily in a placebo controlled, double blind trial. One patient was withdrawn from the trial because of severe postural hypotension with the highest dose. Erect and supine blood pressure in the remaining 14 patients were significantly reduced by all doses of nifedipine. The drug was well tolerated but plasma potassium fell by $0.3 \mathrm{mmol}(\mathrm{mEq}) / 1$ during treatment $(\mathbf{p}<0.05)$.
\end{abstract}

Nifedipine is thus effective in the treatment of hypertension but should probably be used in combination with a potassium sparing diuretic.

\section{Introduction}

In most cases hypertension is adequately controlled by a beta blocker, diuretic, or a combination of these. A few patients, however (almost one tenth in one study), require a third drug. ${ }^{1}$ Unfortunately, many third line agents have serious side effects -for example, the lupus syndrome with hydralazine, ${ }^{2}$ hirsutism and fluid retention with minoxidil, ${ }^{3}$ and diabetes with diazoxide ${ }^{4}$ -and there is a need for new safer drugs. Calcium antagonists such as nifedipine and verapamil have been widely used in the treatment of angina pectoris. As they relax arteriolar smooth muscle ${ }^{5}$ they also reverse the main haemodynamic abnormality in essential hypertension. ${ }^{6}$ Nifedipine has been shown to lower blood pressure as effectively as beta blockers, ${ }^{7}$ but its use as sole antihypertensive treatment is limited by side effects. ${ }^{8}$ Unlike verapamil, nifedipine does not cause significant adverse electrophysiological ${ }^{9}$ or negative inotropic effects on the heart ${ }^{10}$ and may safely be combined with a beta receptor blocking agent. ${ }^{71}$ It might therefore be a useful third step antihypertensive agent, if used in combination with a beta adrenergic blocking drug and a diuretic, to minimise its commonest side effects, palpitation and fluid retention.

We conducted a placebo controlled, double blind trial of nifedipine in patients whose hypertension was not controlled by atenolol and bendrofluazide.

\section{Patients and methods}

Fifteen patients (eight men and seven women) attending the hypertension clinic participated in the study. Their mean age was 50 (SD 9) years (range 32-69 years) and all had a diastolic blood pressure greater than $95 \mathrm{~mm} \mathrm{Hg}$ in the erect or supine position on at least two occasions while taking atenolol $100 \mathrm{mg}$ and bendrofluazide $5 \mathrm{mg}$ daily. All had essential hypertension. Patients with other serious systemic disease, diabetes, cardiomegaly visible on chest $x$ ray film, or an abnormal electrocardiogram were excluded. Patients continued

Department of Clinical Pharmacology, Royal Postgraduate Medical School, Hammersmith Hospital, London W12 0HS

M B MURPHY, MRCPI, research fellow and honorary senior registrar A J I SCRIVEN, MRCP, research fellow and honorary registrar C T DOLLERY, FRCP, professor of clinical pharmacology

Correspondence to: Dr M B Murphy. to take atenolol and bendrofluazide throughout the study. Nifedipine was added in increasing doses of $10 \mathrm{mg}, 20 \mathrm{mg}$, and $30 \mathrm{mg}$, each for two weeks three times daily. A two week period of placebo was allocated at random within the eight week study so that the trial was double blind.

Patients were examined on the 14th day of each treatment period, two hours after taking medication. Blood pressure was measured in the right arm after patients had rested supine for 10 minutes. An electronic ultrasonic sphygmomanometer (Roche Ateriosonde) was used and the mean of three readings recorded. The radial pulse was counted for one minute and these measurements were repeated after patients had been standing for three minutes. A blood sample was taken for biochemical analysis and a physical examination was performed. The volume of the left foot was estimated at each visit in seven patients, by measurement of water displaced from an overflow cylinder. Symptomatic side effects were recorded on a standardised questionnaire administered at the end of each treatment period.

Compliance was checked by tablet count and by tablet diaries which the patients completed daily.

All patients gave informed consent and the study protocol was approved by the ethics committee of the Royal Postgraduate Medical School. The statistical tests applied were the paired $t$ test and linear regression analysis and all results are expressed as mean (standard deviation).

\section{Results}

Fourteen patients completed the study and their data are reported. One patient was withdrawn because of severe postural hypotension symptoms with nifedipine $90 \mathrm{mg}$ daily.

The patients had moderate hypertension with combined diuretic and beta adrenergic blockade: mean supine blood pressure was $166 / 101 \mathrm{~mm} \mathrm{Hg}$ and mean erect blood pressure 156/102 $\mathrm{mm} \mathrm{Hg}$. During treatment with placebo there was a small fall in blood pressure compared with that recorded at screening $(11 / 6 \mathrm{~mm} \mathrm{Hg}$ supine and $10 / 7 \mathrm{~mm} \mathrm{Hg}$ erect). The addition of nifedipine resulted in a significant dose dependent reduction in both erect and supine pressures $(\mathrm{p}<$ $0 \cdot 001$ ) (fig 1 and table I). Figure 2 shows the individual changes in mean blood pressure. There was a significant correlation between the

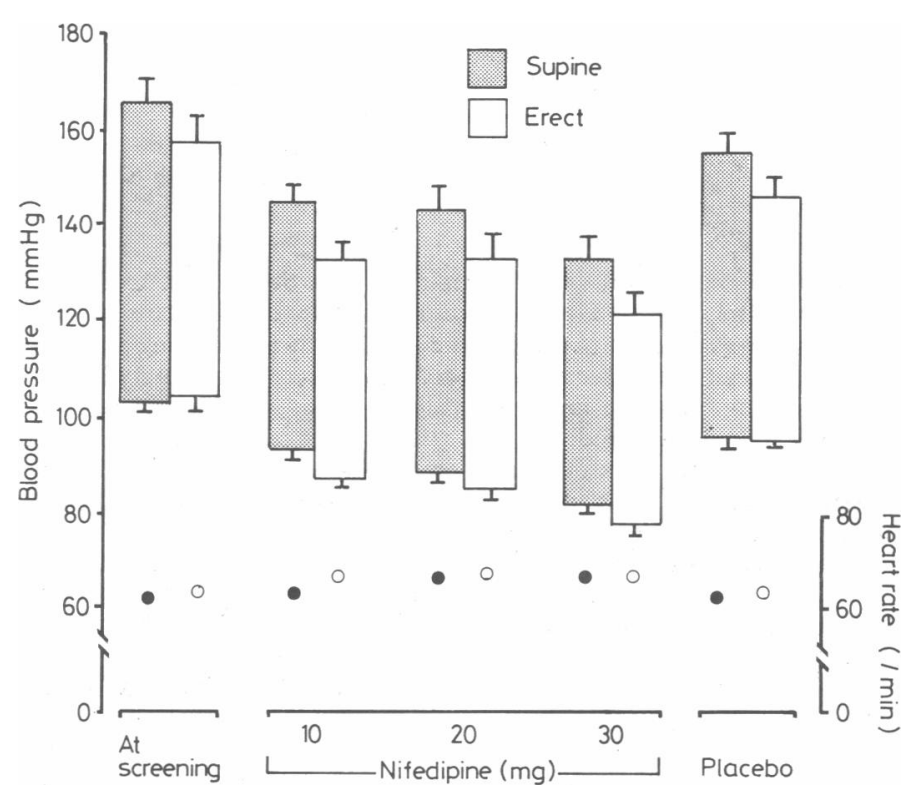

FIG 1-Mean (SEM) supine and erect blood pressure and heart rate in 14 patients before and after treatment with nifedipine 10,20 , and $30 \mathrm{mg}$ three times daily. 
TABLE I-Reduction in blood pressure $(\mathrm{mm} \mathrm{Hg}$ ) in 14 patients receiving nifedipine and placebo. Figures are means (SD)

\begin{tabular}{llllll}
\hline & Screening & \multicolumn{2}{l}{ Nifedipine (three times daily) } & \multirow{2}{*}{ Placebo } \\
\cline { 5 - 6 } & & $10 \mathrm{mg}$ & $20 \mathrm{mg}$ & $30 \mathrm{mg}$ & \\
\hline Supine: & & & & & \\
$\quad$ Systolic & $166(17)$ & $22(16)$ & $24(22)$ & $34(15)$ & $11(16)$ \\
$\begin{array}{l}\text { Diastolic } \\
\text { Erect: }\end{array}$ & $101(5)$ & $11(6)$ & $14(6)$ & $21(9)$ & $6(8)$ \\
$\quad$ & & & & & \\
Systolic & $156(18)$ & $24(16)$ & $25(21)$ & $35(15)$ & $10(18)$ \\
Diastolic & $102(6)$ & $16(8)$ & $18(12)$ & $25(11)$ & $7(9)$ \\
\hline
\end{tabular}

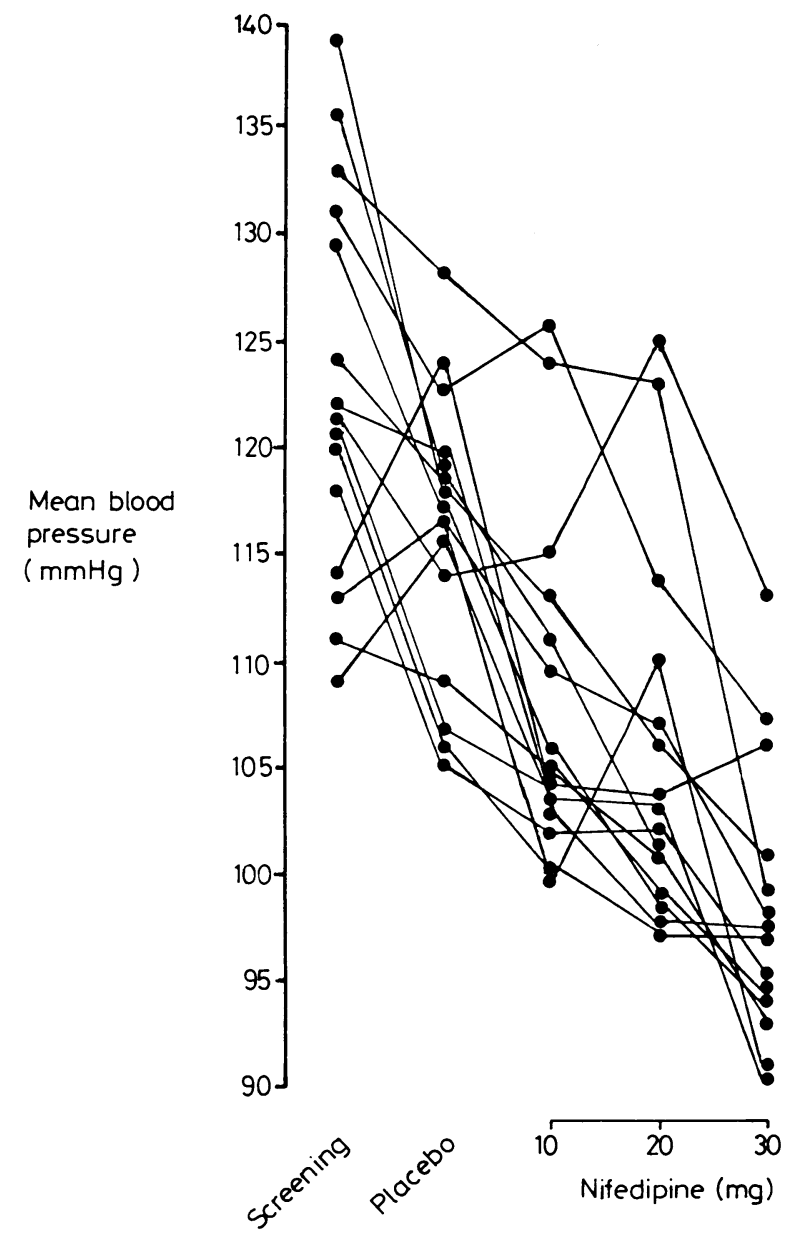

FIG 2-Changes in mean blood pressure in individual patients $(n=14)$ after treatment with nifedipine 10,20 , and $30 \mathrm{mg}$ three times daily, and placebo.

extent of the reduction and the pressure recorded before treatment with nifedipine (fig 3 ). Heart rate did not change significantly when nifedipine was added or when the patient was standing (fig 1), probably because of effective beta receptor blockade by atenolol.

There was no change in random blood glucose concentration or in renal function after nifedipine but there was a small and significant reduction in plasma potassium concentration (table II). Hypokalaemia occurred in 11 of the 14 patients taking nifedipine but was reversed during the placebo period.

The mean foot volume of seven patients increased from 1288 (182) $\mathrm{ml}$ with placebo to 1355 (175) $\mathrm{ml}$ with nifedipine $20 \mathrm{mg}$ three times daily $(\mathrm{p}<0.05)$ and $1372(209) \mathrm{ml}$ with $30 \mathrm{mg}$ three times daily $(\mathrm{p}<0.01)$, although their body weight was hardly altered.

Table III shows the most common side effects in the 14 subjects. Only one patient was unwilling to continue on nifedipine at the end of the study because of nausea, which he also experienced on placebo. The patient who was withdrawn from the trial experienced her postural symptoms after the first $30 \mathrm{mg}$ dose, having taken placebo during the preceding two weeks. She continued to take nifedipine at a lower dose.

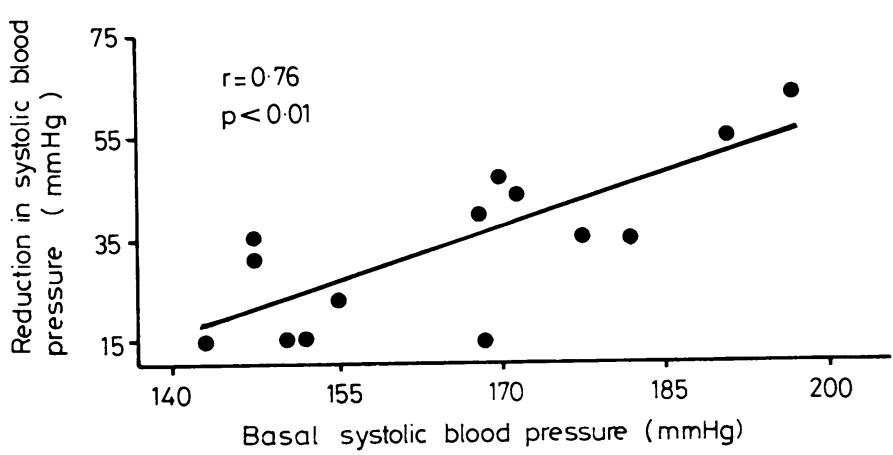

FIG 3-Correlation between reduction in systolic blood pressure ( $\mathrm{mm} \mathrm{Hg}$ ) after nifedipine $30 \mathrm{mg}$ three times daily, and the initial pressure in 14 patients.

TABLE II-Effects of addition of nifedipine on clinical and biochemical indices of 14 patients. Figures are mean $(S D)$

\begin{tabular}{|c|c|c|c|c|c|}
\hline & \multirow{2}{*}{ Screening } & \multirow{2}{*}{ Placebo } & \multicolumn{3}{|c|}{ Nifedipine (three times daily) } \\
\hline & & & $10 \mathrm{mg}$ & $20 \mathrm{mg}$ & $30 \mathrm{mg}$ \\
\hline Body weight $(\mathrm{kg})$ & $80 \cdot 1(12 \cdot 3)$ & $80 \cdot 3(13 \cdot 2)$ & $80 \cdot 2(12 \cdot 7)$ & $80 \cdot 6(12 \cdot 7)$ & $80 \cdot 5(12 \cdot 6)$ \\
\hline $\begin{array}{l}\text { Plasma sodium } \\
(\text { mmol/1) }\end{array}$ & $140 \cdot 5(2 \cdot 3)$ & $141 \cdot 6(2 \cdot 4)$ & $140 \cdot 8(1 \cdot 7)$ & $141 \cdot 3(2 \cdot 2)$ & $139 \cdot 9(2 \cdot 5)$ \\
\hline $\begin{array}{l}\text { Plasma potassium } \\
\text { (mmol/1) } \\
\text { Plasma creatinine }\end{array}$ & $3 \cdot 8(0 \cdot 4)$ & $3.9(0.5)$ & $3.6(0.4)$ & $3.6(0.5)$ & $3.5(0.5)^{*}$ \\
\hline $\begin{array}{l}\text { Plasma creatinine } \\
(\mu \mathrm{mol} / 1)\end{array}$ & $90 \cdot 4(16)$ & $97 \cdot 2(17 \cdot 1)$ & $89 \cdot 8(18 \cdot 3)$ & $94 \cdot 3(15 \cdot 5)$ & $96 \cdot 0(15 \cdot 9)$ \\
\hline glucose $(\mathrm{mmol} / \mathrm{l})$ & $5 \cdot 8(1 \cdot 2)$ & $5 \cdot 9(2 \cdot 1)$ & $6 \cdot 1(1 \cdot 8)$ & $5 \cdot 7(1 \cdot 8)$ & $6 \cdot 2(1 \cdot 8)$ \\
\hline
\end{tabular}

${ }^{*} \mathrm{p}<0.05$.

Conversion: $S I$ to traditional units-Sodium: $1 \mathrm{mmol} / 1 \approx 1 \mathrm{mEq} / 1$. Potassium: $1 \mathrm{mmol} / 1 \approx 1 \mathrm{mEq} / 1$. Creatinine: $1 \mu \mathrm{mol} / 1 \approx 0.01 \mathrm{mg} / 100 \mathrm{ml}$. Glucose: $1 \mathrm{mmol} / 1 \approx$ $18 \mathrm{mg} / 100 \mathrm{ml}$.

TABLE III-Side effects reported by 14 patients receiving placebo and nifedipine

\begin{tabular}{|c|c|c|c|c|c|}
\hline & \multirow{2}{*}{ Screening } & \multirow{2}{*}{ Placebo } & \multicolumn{3}{|c|}{ Nifedipine (three times daily) } \\
\hline & & & $10 \mathrm{mg}$ & $20 \mathrm{mg}$ & $30 \mathrm{mg}$ \\
\hline $\begin{array}{l}\text { Postural dizziness } \\
\text { Limb weakness } \\
\text { Headaches } \\
\text { Nasal obstruction } \\
\text { Flushing } \\
\text { Palpitation } \\
\text { Ankle oedema } \\
\text { Nausea }\end{array}$ & $\begin{array}{l}3 \\
2 \\
3 \\
5 \\
3 \\
3 \\
0 \\
1\end{array}$ & $\begin{array}{l}2 \\
2 \\
0 \\
5 \\
1 \\
2 \\
0 \\
1\end{array}$ & $\begin{array}{l}2 \\
2 \\
2 \\
7 \\
3 \\
2 \\
1 \\
1\end{array}$ & $\begin{array}{l}5 \\
3 \\
1 \\
6 \\
4 \\
2 \\
2 \\
1\end{array}$ & $\begin{array}{l}5 \\
5 \\
1 \\
5 \\
4 \\
2 \\
2 \\
1\end{array}$ \\
\hline
\end{tabular}

\section{Discussion}

These results have established the hypotensive efficacy of nifedipine in combination with a beta blocker and diuretic. The extent of the reduction of blood pressure was similar to that recently reported in another controlled study ${ }^{12}$ and a further uncontrolled one. ${ }^{13}$ It compares favourably with that attributed to hydralazine in a similar study by Wilcox et al. ${ }^{14}$ In Wilcox's study, the addition of hydralazine $50 \mathrm{mg}$ twice daily in patients receiving atenolol and bendrofluazide (in the same dose as in our study), resulted in a reduction of only $6 \mathrm{~mm} \mathrm{Hg}$ in diastolic blood pressure and no change in systolic pressureconsiderably less than that seen after nifedipine in our study. Furthermore, the calcium antagonist appeared to have the greatest effect in patients with the highest pressure. Analysis of the dose response relation suggests that the response curve is rather flat, as trebling the dose of nifedipine increased the hypotensive effect by only $50 \%$. The similarity of the responses to doses of $30 \mathrm{mg}$ and $60 \mathrm{mg}$ daily is probably explained by the poor compliance of two of the patients while taking $60 \mathrm{mg}$ daily. Figure 2 illustrates this and the progressive reduction in pressure in the other subjects as the nifedipine dose increased.

Previous studies of nifedipine as sole treatment have reported a high prevalence of side effects, particularly palpitation and 
oedema. ${ }^{8}$ Combining nifedipine with a beta blocker prevented tachycardia, both erect and supine, and the diuretic abolished fluid retention. The evening ankle oedema reported by two of our patients and the increased foot volume in the absence of weight gain in seven patients was probably due to fluid redistribution, as arteriolar dilatation by the calcium antagonist without venodilatation ${ }^{15}$ should result in enhanced capillary transudation.

The reduction in plasma potassium concentration was unexpected and was undoubtedly due to nifedipine, as the concentrations returned to pretreatment values during placebo treatment. As nifedipine is also a renal artery dilator it may potentiate the kaliuretic effect of the thiazide diuretic. A less likely explanation is that the baroreflex induced catecholamine release seen with nifedipine ${ }^{16}$ could promote beta ${ }_{2}$ adrenergic receptor mediated potassium influx into cells. ${ }^{17}$ This would be maximal about one to two hours after vasodilator dosage-the time at which our patients were studied. Such a hypokalaemic effect has not, however, been noted after other vasodilators with similar effects on the baroreflex. Although small ( $0.3 \mathrm{mmol}(\mathrm{mEq}) /$ 1), this reduction in plasma potassium may be important in patients with pre-existing diuretic induced hypokalaemia. Recent reports that hypokalaemia may predispose to cardiac arrhythmias $^{18}$ suggest that nifedipine might best be combined with a potassium sparing diuretic.

There is some disquiet about the long term adverse metabolic effects of current antihypertensive treatment. ${ }^{19}$ One interpretation of the recent Multiple Risk Factor Intervention Trial has suggested that diuretics may increase mortality from coronary artery disease in hypertensive patients with an abnormal electrocardiogram. ${ }^{20}$ On the other hand, evidence is accumulating that calcium antagonists may have beneficial effects on factors reputedly involved in the pathogenesis of coronary thrombosis: nifedipine may inhibit platelet aggregation $^{21}$; it prevents the development of atherosclerosis in rats eating high fat diets ${ }^{22}$; and it relaxes coronary arterial spasm in man. They thus merit more extensive evaluation as antihypertensive treatment. Most studies to date, although proving the hypotensive efficacy of calcium antagonists, which is comparable to that of beta blockers and diuretics, have inadequately documented their side effects. The prevalence of side effects will ultimately determine their role whether as first line treatment or only in combination with other agents. Meanwhile, this study has shown that nifedipine is an effective, well tolerated third line drug, an alternative to currently available vasodilators.

\section{References}

1 Beilin LJ, Bulpitt CJ, Coles EC, et al. Long term anti-hypertensive drug treatment and blood pressure control in three hospital hypertension clinics. Br Heart $\mathcal{F} 1980 ; 43: 74-9$.

${ }^{2}$ Perry HM, Schroeder HA. Syndrome simulating collagen disease caused by hydralazine (Apresoline). $\mathcal{F} A M A$ 1954;154:670-3.

${ }^{3}$ Dargie HJ, Daniel J, Dollery CT. Minoxidil in resistant hypertension. Lancet 1977 ;ii :515-8.

Updike SJ, Harrington AR. Acute diabetic ketoacidosis-a complication of intravenous diazoxide treatment for refractory hypertension. $N$ Engl f Med 1969;280:768.

${ }^{5}$ Bartorelli C, Magrini F, Moruzzi P, et al. Haemodynamic effects of a calcium antagonistic agent (nifedipine) in hypertension: therapeutic implications. Clinical Science and Molecular Medicine 1978;55:suppl 291-2.

'Dunstan HP, Tarazi RC, Hinshaw LB. Mechanisms controlling arterial pressure. In: Frolich ED, ed. Pathophysiology. 2nd ed. Philadelphia: J B Lippincott, 1976:49.

${ }_{7}^{7}$ Harris L, Dargie HJ, Lynch PG, Bulpitt CJ, Krikler DM. Blood pressure and heart rate in patients with ischaemic heart disease receiving nifedipine and propranolol. Br Med $\mathcal{F} 1982 ; 284: 1148-51$.
${ }^{8}$ Ebner F, Dunschede HB. Haemodynamics, therapeutic mechanism of action, and clinical findings of Adalat use based on worldwide clinical trials. In: Jatene AD, Lichtlen PR, eds. 3rd international Adalat symposium. Amsterdam: Excerpta Medica, 1976:283-300.

9 Mitchell LB, Schroeder JS, Mason JW. Comparative clinical electrophysiologic effects of diltiazem, verapamil and nifedipine: a review. Am $\mathcal{F}$ Cardiol 1982;49:629-33.

${ }^{10}$ Henry P. Comparative pharmacology of calcium antagonists: nifedipine, verapamil and diltiazem. Am $\mathcal{F}$ Cardiol 1980;46:1047-58.

${ }^{11}$ Aoki K, Kondo S, Mochizuki A, et al. Antihypertensive effect of cardiovascular calcium antagonist in hypertensive patients in the absence and presence of beta adrenergic blockade. Am Heart $\mathcal{F}$ 1978;96:218-26.

12 Bayley S, Dobbs RJ, Robinson BF. Nifedipine in the treatment of hypertension: report of a double-blind controlled trial. Br $\mathcal{F}$ Clin Pharmacol 1982;14:509-12.

13 Dean $S$, Kendall MJ. Nifedipine in the treatment of difficult hypertensives. Eur $\mathcal{F}$ Clin Pharmacol 1983;24:1-5.

14 Wilcox RG. Combination hypotensive therapy with atenolol, bendrofluazide and hydralazine. Postgrad Med 7 1977;53,suppl 3:128-33.

15 Robinson BF, Dobbs RJ, Kelsey CR. Effects of nifedipine on resistance vessels, arteries and veins in man. Br $\mathcal{F}$ Clin Pharmacol 1980;10:433-8.

${ }^{16}$ Murphy MB, Scriven AJI, Brown MJ, Causon R, Dollery CT. The effects of nifedipine and hydralazine induced hypotension on sympathetic activity. Eur $\mathcal{F}$ Clin Pharmacol 1982;23:479-82.

17 Struthers AD, Reid JL, McLean K, Rodger JC. Adrenaline, hypokalaemia and cardiac arrhythmias: effect of beta adrenoceptor antagonists [Abstract]. Clin Sci 1982;62:1.

${ }^{18}$ Dyckner $T$, Helmners $C$, Lundman $T$, Wester PO. Initial serum potassium level in relation to early complications and prognosis in patients with acute myocardial infarction. Acta Med Scand 1975;197:207-10.

${ }^{19}$ Murphy MB, Lewis PJ, Kohner EM, Schumer B, Dollery CT. Glucose intolerance in hypertensive patients; a 14 year follow-up. Lancet 1982 ;ii:1293-5.

${ }^{20}$ Multiple Risk Factor Intervention Trial (MRFIT) Research Group. Risk factor changes and mortality results. $\mathcal{f} A M A 1982 ; 248: 1465-77$.

${ }^{21}$ Johnsson $H$. Effects of nifedipine (Adalat) on platelet function in vitro and in vivo. Thromb Res 1981 ;21:523-8.

${ }^{22}$ Henry PD, Bentley KI. Suppression of atherogenesis in cholesterol-fed rabbit treated with nifedipine. $\mathcal{F}$ Clin Invest 1981 ;68:1366-9.

(Accepted 26 April 1983)

DISCUSSIVE MEDICINES-The nature of discussing (or sweating) medicines is almost the same with attractive, for there are no discussive medicines but are attractive, nor scarce any attractive medicine but is in some measure or other discussing. The difference then is only this; that discussive medicines are hotter than attractive, and therefore nothing else need be written of their nature. Their use may be known even from their very name; for diseases that come by repletion or fulness, are cured by evacuation or emptying; yet neither blood nor gross humours are to be expelled by sweating, or insensible transpiration (as they call it) but the one requires blood-letting, the other purgation, but scrosus or thin humours and filthy vapours, and such like superfluities, are to be expelled by sweat, and be wary in this too, for many of them work violently, and violent medicines are not rashly to be given. Besides, swellings are sometimes made so hard by sweating medicines, that afterwards they can never be cured; for what is thin being by such medicines taken away, nothing but what is perfectly hard remains: If you fear such a thing, mix emolients with them. Again, sometimes by using discussives, the humours offending (which physicians usually call the peccant humours) is driven to some more noble part of the body, or else it draws more than it discusseth; in such cases, concoct and attenuate the matter offending before you go about to discuss it. From hence may easily be gathered at what time of the disease discussive medicines are to be used, viz about the declining of the disease, although in diseases arising from heat of blood, we sometimes use them in the encrease and state of them. They are known by the same marks and tokens attenuating medicines are, viz by their burning and biting quality, they being very hot, and of thin parts, void of any biting quality, therefore they contract not the tongue in tasting of them. (Nicholas Culpeper (1616-54) The Complete Herbal, 1850.) 